\title{
Specialized training through European Masters on environmental management and its risks and threats: Innovative teaching strategies and methodologies.
}

\author{
J.C. Santamarta ${ }^{1}$, M.P. Arraiza ${ }^{2}$, F. Ioras ${ }^{3}$, L. Hernández-Gutiérrez ${ }^{4}$, \\ J. Neris ${ }^{5}$, I. Abrudan ${ }^{6}$, J. V. López ${ }^{2}$.J.Rodríguez-Martín \\ ${ }^{1}$ Technical School of Civil and Industrial Engineering, Universidad de La Laguna, Spain. \\ ${ }^{2}$ Technical School of Forestry Engineering, Technical University of Madrid, Spain. \\ ${ }^{3}$ Buckinghamshire New University, High Wycombe, Bucks, UK. \\ ${ }^{4}$ Canary Islands Goverment. Tenerife, Canary Islands, Spain \\ ${ }^{5}$ Department of Soil Science and Geology, University of La Laguna, Spain. \\ ${ }^{6}$ Transilvania University of Brasov, Romania. \\ ${ }^{7}$ SATOCAN SA. Tenerife. Canary Islands. Spain
}

\begin{abstract}
The study of climate change and degraded land requires the study of causal relations between human causes and land use changes. Specialized training through European Masters on environmental management and its risks and threats will dynamically link people from different disciplines and from outside academia to improve students' experience which will enable them to learn to deal with multi disciplinary decision making solution. This will allow for students not to be just inserted into one system or discipline, but simultaneously into a process of learning about the relation between education, political, social, ecological and economic environment.
\end{abstract}

But the most innovative aspect of these teaching strategies and methodologies is the link created between teaching innovation and environmental disciplines. There is not such an offer that combines and links these two major aspects directly related and focuses the educational program in this combination. From this perspective, which is widely recognized by experts, students will have an innovative and useful learning experience on the issue covered by the program.

Keywords: Master Erasmus, on-line resources, environmental management, natural risk,Learning Analytics

\section{Introduction}

Europe is facing an accelerated climate change as a result of global warming and as a result population departure and consequent abandon of rural areas due to the increase floods, forest fire, lack of water, land slide, etc, and there is a need to find ways to support management of such hazards by providing adequate training on environmental security and management.

EU Policy on Climate Change (WHO/Europe, Parma Italy, 2010) for member states envisage to strengthen health, social and environment systems and services to improve their capacity to prevent, prepare for and cope with climate change. Within this context the consortium of this project evaluated EU' HE offer on Climate Change and Degraded 
Land to identify if the next generation of environmental scientists and managers are presented with a solid and well prepared curricula. A survey of existing curricula at educational institutions in partner institutions was conducted and followed by a thorough analysis. This survey covered the ways how the practice is organized for students. This and all other data was discussed in the preparatory phase of the project idea. The proposed project draw lessons from this evaluation identified educational practices that need to change to embrace climate change and land degradation and restoration as a subject, gaps in education from employers and professional's perspective. Based on this a MSc program of modules will be accredited jointly or dually at partner institutions and the overall MSc will be jointly piloted by the consortium leader, Buckinghamshire New University (UK) with the intention to offer restoration of degraded land within a transdisciplinary context with enterprises support and endorsement; and opportunities, such as internships and other methods of applied learning, are included in the curriculum as a result of the partnership with stakeholders. All partners will participate in the piloting of the MSc on Climate Change, and Restoration of Degraded Land and will also include accredited modules in their accredited MSc programs offer with the intention of joint delivery [1]

The target group is Engineers, Graduates of Business and Planning faculties who intend to work in the infrastructure projects, graduates of environmental faculties who intend to specialise in environment disasters management, fire fighters who intend to specialise in wildfire prevention, graduates who intend to get specialized in environmental restoration and its protection.

\section{Methodology}

The Masters programs on environmental issues try to be a reference in the use of teaching innovation methodologies.

One of the strategies is the use of Learning Analytics, which is based on analyzing data given by students in their formative and learning processes. The objective is to use such information to improve the learning process itself. Data can be obtained through the different technologies currently used in learning; such technologies can be corporative (for instance LMS Systems such as Moodle), owned by students (mobile, tablet, laptop) or even social (networks, blogs...).

To the compiled info, decision making processes, model building data mining and automatic learning are applied, all that in order that the course, the teaching staff and the students have helping tools. In the case of students for example, it is done by adapting resources or training plans. In the case of teaching staff, it is intended to help them to know the results of their teaching strategies, to attend the diversity, personal backing plans, and for the course, by adopting teaching policies, effective distribution of resources. Therefore, the problem of the Learning Analytics is not so much the technology but how to determine which data is relevant (and to capture it) for the improvement of the learning processes, the modeling of the student and teaching staff behaviors and the establishment of the most adequate diagnostics and resources for every model Nevertheless, currently the Learning Analytics can help us solve some problems in which we are immerse; for instance, it is an excellent tool for diagnostic and learning auto assessment, for the adaptation of learning resources, for improving the personalized planning and for proactive tutorships. It can also serve for establishing models associated to competences (as well as validating their efficiency). 


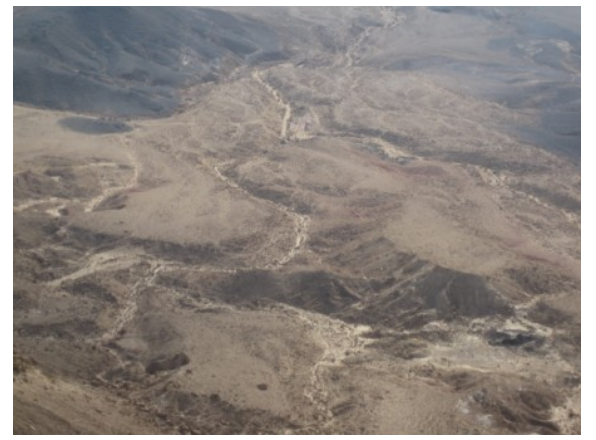

Fig. 1: (Above) Degradation and erosion processes in Israel.

Also, the use of Web 2.0 technologies (blogs, wikis and social networks) is also referred, enabling different cooperative models, where participants are at the same time builders and beneficiaries. Cooperative models have been applied quite for a while (usually framed in knowledge management projects).

Practical trip aid to meet educational objectives, such are: to get basic knowledge and skills to manage, develop, design and understand civil engineering projects, to be able to integrate concepts when information is limited or incomplete, to develop abilities for communication and reasoning, to give them skills to learn in the future like a part of their educational career [2].

In the case of using digital blackboards, their functionality consists in projecting, on a screen situated in a relevant place of the classroom, any type of information from the $\mathrm{PC}$, internet or any other analog or digital device connected to the system: TV antenna, video projector, video camera, etc. In classrooms provided with digital blackboard, students and teachers can visualize and comment in groups all the information available on Internet or other resources: documents and digitalized pictures (notes, class works, etc.), teaching CDs, multimedia presentations, videos, paper documents (which can be catch by simple webcam), etc.

This availability of all kinds of information in the classroom and the possibility of joint visualization facilitates lead to the development of cooperative work by groups of students and subsequent public presentation to the whole classroom [4].

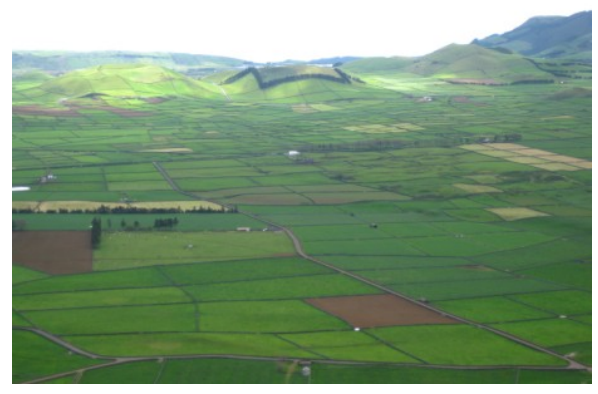

Fig. 2: Landscape of intensive crops in the Azores Islands.

The Portfolio is a method of teaching, learning and assessment based on the contribution of different types of deliverables by students, through which they can judge their abilities within a discipline or field of study. These deliverables report the process followed by the students, allowing them and others to see their efforts and achievements in relation to the learning objectives and evaluation criteria previously established. It is a method that allows to unite and to coordinate a set of evidences in order to issue an assessment as close to reality as possible that is difficult to acquire with other assessment methods which give a more fragmented view.

In the postgraduate course raised teamwork will be enhanced through interaction to enable knowledge increase. Therefore, one needs to enter multiple alternative classrooms, including teamwork.

In the process of teaching and learning, teamwork is a relevant methodology to 
reach common goals, through dialogue, communication and participation of all group members. Teamwork implies to discover the strengths and weaknesses of the people in it. Also involves analyzing the mechanisms to continuously improve the dynamics of the whole group [3].

\section{Conclusions}

It is clear that the expansion of resources in the classroom is essential to potentiate the study, to improve the motivation of teacher and student, to meet the objectives and of course for the resolution of learning problems that can occur in classic and habitual frames.

Such approach is a resultant of teacher's work in lecturers, constant update and ongoing acquisition of knowledge, and the application of new technologies.

\section{Acknowledgements}

This work has been developed in the framework of the INGENIA Research Group from the Universidad de La Laguna. It has been founded by the European Union under projects 517629 - LLP - 1 2011 - UK - ERASMUS - EMCR and
526746 - LLP - $1-2012$ - ES ERASMUS - EMCR.

\section{References}

[1] SantamartaCerezal, J.C. Arraiza, M.P. Ioras, F. Lópéz, J.V., Engineering 2.0, new digital strategies in technical education,EDULEARN12 Proceedings, Barcelona 2012

[2] Menéndez Pidal, I. SantamartaCerezal, J.C. Hernández Gutiérrez L.E. Sanz Pérez, E, Learning experience on applied geology in civil engineering curricula by using university cooperation and practical trips, EDULEARN11 Proceedings, Barcelona 2010.

[3] Santamarta Cerezal, J.C. Hernández Gutiérrez L.E. Arraiza, M.P. Neris Tomé, J. Análisis de nuevas estrategias para la mejora del aprendizaje en enseñanzas técnicas dentro del Espacio Europeo de Educación Superior. Servicio de Publicaciones de la Universidad de La Laguna, 2012.

[4] MarquèsGraells P. La pizarra digital en el aula de clase, Ed. EDEBE, Barcelona. 